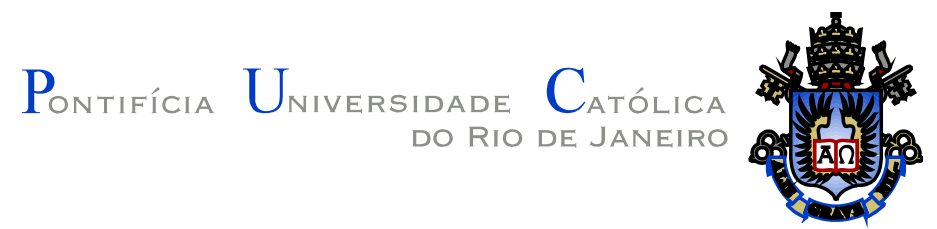

Emanuel Mello Mattos de Castro

\title{
O Perspectivismo em Deleuze
}

\section{Dissertação de Mestrado}

Dissertação apresentada como requisito parcial para obtenção do grau de Mestre pelo programa de Pós-Graduação em filosofia do Departamento de Filosofia da PUC-Rio.

Orientadora: Profa ${ }^{a}$. Déborah Danowski

Rio de Janeiro

Abril de 2015 


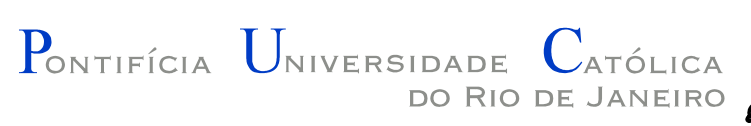

\section{Emanuel Mello Mattos de Castro \\ Deleuze e o Perspectivismo}

Dissertação apresentada como requisito parcial para a obtenção do grau de Mestre pelo Programa de Pós-Graduação em Filosofia do Departamento de Filosofia do Centro de Teologia e Ciências Humanas da PUC- Rio. Aprovada pela Comissão Examinadora abaixo assinada.

Profa. Deborah Danowski

Orientadora

Departamento de Filosofia - PUC-Rio

Prof. Rodrigo Guimarães Nunes Departamento de Filosofia - PUC-Rio

Prof. Ovidio de Abreu Filho Universidade Federal Fluminense - UFF

Profa. Denise Berruezo Portinari Coordenadora Setorial do Centro de Teologia e Ciências Humanas - PUC-Rio 
Todos os direitos reservados. É proibida a reprodução total ou parcial do trabalho sem autorização da universidade, do autor e do orientador.

\section{Emanuel Mello Mattos de Castro}

Graduou-se em Filosofia pela Pontifícia Universidade Católica do Rio de Janeiro (PUC-Rio) em 2012.

Ficha Catalográfica

Castro, Emanuel Mello Mattos de

O perspectivismo em Deleuze / Emanuel Mello Mattos de Castro; orientadora: Déborah Danowski. - 2015.

105 f. ; $30 \mathrm{~cm}$

Dissertação

(mestrado)-Pontifícia Universidade Católica do Rio de Janeiro, Departamento de Filosofia, 2015.

Inclui bibliografia

1. Filosofia - Teses. 2. Deleuze 3. Perspectivismo. 4. Ponto de vista. I. Danowski, Déborah. II. Pontifícia Universidade Católica do Rio de Janeiro. Departamento de Filosofia. III. Título.

CDD: 100 
À minha companheira, Bia, que dedica sua vida à floresta. 


\section{Agradecimentos}

Sendo um texto sobre Perspectivismo, agradeço a inestimável contribuição de minha orientadora Déborah Danowski, ponto de vista claro e distinto em contraponto ao meu, confuso e obscuro. Sem suas observações e correções, enfim, sem sua perspectiva, este não seria possível. Agradeço em especial sua paciência e dedicação infinitas.

Ao meu pai, Marcos de Castro, que, além de tudo, ainda me auxiliou nas

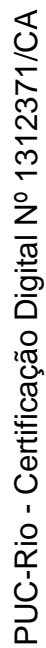
traduções.

Aos povos do Tapajós e do Trombetas, rios que me ensinaram sobre Variação. 


\section{Resumo}

Castro, Emanuel Mello Mattos; Danowski, Déborah. Deleuze e o Perspectivismo. Rio de Janeiro, 2015. 105p. Dissertação de Mestrado Departamento de Filosofia, Pontifícia Universidade Católica do Rio de Janeiro.

A pesquisa centra-se na importância do conceito de Perspectivismo na filosofia de Gilles Deleuze. Procurando desarticular a forma-Sujeito, para Deleuze pontos de vista têm a ver com diferenças e não com identidades; a constituição não de sujeitos e objetos, mas de perspectivas ou pontos de vista. Em Deleuze, o perspectivismo não é a relatividade do verdadeiro, mas a verdade da relatividade.

\section{Palavras-chave}

Perspectivismo; Ponto de vista; Deleuze. 


\section{Abstract}

Castro, Emanuel Mello Mattos; Danowski, Déborah (Advisor). Deleuze and Perspectivism. Rio de Janeiro, 2015. 105p. MSc. Dissertation Departamento de Filosofia, Pontifícia Universidade Católica do Rio de Janeiro.

This research focuses on the importance of the concept of Perspectivism in Gilles Deleuze's philosophy. Trying to dismantle the Subject form, for Deleuze points of view have to do with differences rather than identities; not the constitution of subjects and objects, but perspectives or points of view. In Deleuze, perspectivism isn't the relativity of the true, but the truth of relativity.

\section{Keywords}

Perspectivism; Point of view; Deleuze. 


\section{Sumário}

$\begin{array}{ll}\text { 1. Introdução } & 10\end{array}$

$\begin{array}{ll}2 . & 13\end{array}$

3. Perspectivismo do tempo 44

4. Variações e ponto de vista 62

$\begin{array}{lll}\text { 5. Conclusão } & 88\end{array}$ 
Preencher um espaço, partilhar-se nele, é muito diferente de partilhar o espaço. É uma distribuição de errância e mesmo de 'delírio', em que as coisas se desdobram em todo o extenso de um Ser unívoco e não-partilhado. Não é $o$ ser que se partilha segundo as exigências da representação; são todas as coisas que se repartem nele na univocidade da simples presença.

Gilles Deleuze, Diferença e Repetição

Toute expérience d'une autre pensée est une expérience sur la nôtre.

Eduardo Viveiros de Castro, Métaphysiques Cannibales 